\section{An unusual cause of abnormal gait}

\author{
Huw M. Perry MB \\ Department of Public Health Medicine, West \\ Glamorgan Health Authority, Swansea, UK
}

\section{Sir}

Peripheral nerve injuries from intramuscular injections are recognized complications when administering drugs in a healthcare setting.

I report two cases of possible peripheral nerve damage in people illicitly injecting anabolic steroids into the gluteal region for improvement in muscular strength and size.

This report concerns two men who attended the same needle exchange scheme to obtain clean needles and syringes for their anabolic steroid misuse. Both patients suffered lower limb, hamstring weakness using the hip flexor as a compensatory mechanism for movement. There also appeared to be ill-defined anaesthesia and paraesthesia below the knee in both individuals. Each individual described bizarre injecting techniques. One client divided the buttocks into quadrants and injected into each quadrant, then into the centre of the intersecting lines in turn.

The second patient's history of injection technique was more frequently towards the centre of the buttock. Both these cases were seen to suffer similar symptoms of possible sciatic or peripheral nerve trauma. When it was suggested they seek medical help neither patient was ever seen again.

Anabolic steroids misuse is now getting more publicity. Estimates on the prevalence of steroid use are found in the literature. A recent study by the author has shown that in some gymnasia in South Wales the prevalence is over $35 \%{ }^{1}$. Korkia and Stimson $^{2}$ found that the prevalence of anabolic steroid use in the gyms studied ranged from no reports to $46 \%$ of respondents and that $9 \%$ of men and $2 \%$ of women from their study cohort reported having used anabolic steroids at some time.

Our needle exchange schemes are progressive in that they acknowledge the need to provide a service to clients taking anabolic steroids as well as those taking illicit drugs and in that drug users are taught safer injecting techniques for intravenous (i.v.) administration, we also offer advice on intramuscular (i.m.) injecting. With the prevalence of anabolic steroid misuse, we feel sure that more complications of administration will be seen in the future.

One problem with this group of individuals is that they refuse to acknowledge themselves as drug misusers and consequently are slow in seeking specialist advice. Also, on occasions, their pharmaco-

(C) 1994 Butterworth-Heinemann Ltd 0306-3674/94/010060-03 logical and technical knowledge of injecting is far less than that of i.v. drug abusers.

Healthcare professionals involved with these misusers should bear the above cases in mind when they come into contact with people using anabolic steroids. They should offer advice on injecting techniques just as they do for i.v. abusers, if as my experience indicates, abstinence, although a longterm ideal, is not agreeable to these individuals in the short term.

\section{References}

1 Perry HM, Wright D, Littlepage BNC. Dying to be big: a review of anabolic steroids. Br J Sports Med 1992; 26: 259-61.

2 Korkia P, Stimson GV. Anabolic Steroid Use in Great Britain. The Centre for Research on Drugs and Health Behaviour, London, UK, 1993.

\section{Electrolyte manipulation in female body-builders}

\section{Roy J. Shephard MD PhD DPE}

School of Physical and Health Education, 320 Huron

Street, Toronto, Ontario M5S 1A1, Canada

\section{Sir}

The 'making of weight' by drastic restriction of food and fluid intake, administration of diuretics and purgatives, blood donation, deliberate vomiting, the wearing of impermeable suits and prolonged sauna bathing, is a well-recognized abuse in combat sports and other weight-classified athletic contests ${ }^{1-4}$. However, it is less widely recognized that entrants in top body-building competitions now also engage in dangerous manipulations of body fluids and electrolytes.

One 'coach' of body builders in Western Canada now recommends stringent dietary and pharmacological manipulation for 7 to 10 days before major international competitions. The stated objectives of the regimen are to make the skin 'paper thin', and the muscles smooth and prominent by intracellular fluid accumulation carried to the threshold of water intoxication on the day of the contest.

The 'coach' is presently advocating 'medically supervised' (!) administration of the aldosterone antagonist spironolactone (aldactone) in doses increasing from 50 to $100 \mathrm{~g}$ (sic!) per day in order to increase intracellular water. If spironolactone cannot be obtained, he suggests that the electrolyte regulating systems of the body can be 'tricked' into accepting a high intracellular potassium by a period of 2-3 days of high salt intake, avoiding all food with an appreciable potassium content; this is followed by a similar 3-4 day period when all salt is eliminated from the diet, high sodium foods are avoided, and foods high in potassium are exclusively selected. The 'coach' thoughtfully warns that a combination of the 
high potassium diet with large doses of spironolactone could be dangerous! He further proposes that with either the high potassium or the spironolactone regimen, the normal fluid intake be supplemented by the drinking of 10-15 glasses of distilled water over each of the 3 days before competition.

The effects of such mineral ion manipulation upon muscle water content are further supplemented by glycogen depletion (pushed to a state of 'borderline ketosis', as an initial allowance of $92 \mathrm{gday}^{-1}$ is tapered to $23 \mathrm{~g} \mathrm{day}^{-1}$ over the period 7-4 days before competition), with a final period of 'supercompensation', when 10 separate 40 -g carbohydrate meals are taken at 90 -min intervals. The sources of carbohydrate are limited to items such as bananas, raisins, dates, yams, tomatoes, apricots and peaches, the objective being to maximize the intake of potassium, and to minimize the intake of sodium. If the muscles still appear 'flat' on the day before competition, the intake of these carbohydrates is further boosted to $40 \mathrm{~g} \mathrm{~h}^{-1}$. Protein ( $1 \mathrm{~g} \mathrm{~kg}^{-1}$ of body mass) is taken as dry curd, with the objective of further minimizing sodium intake.

After the weigh-in, the 'coach' allows no further fluids until judging has been completed. A sauna to the point of sweating is taken on the day before competition, and again on the morning of competition. The competitor is told to remain lying down for as much of the final $24 \mathrm{~h}$ as possible, in the hope of achieving an even distribution of oedema fluid. One hour before judging, $100 \mathrm{~g}$ of liquid protein is ingested, and half an hour before competition, the competitor also seeks to boost blood sugar by drinking three-quarters of a cup of liquid honey. The stated intent of this practice is to combine muscle oedema with the desired paper thin skin.

It is regrettable to see one more form of international competition where coaches are misunderstanding and abusing the expertise of the physiologist in a search for competitive advantage. Moreover, the manipulation of intracellular water content by rigorous dieting and/or the administration of spironolactone carries a considerable risk to health, especially when those who advocate such practices make no attempt to monitor blood electrolytes, and are unclear on the difference between a 100-mg dose and a 100-g poisoning with aldactone!

Most entrants in body-building contests are not of an age where cardiac problems would be anticipated, but the combination of heavy weight-lifting with high plasma potassium levels could provoke a lethal cardiac arrhythmia. I am not aware that any of the victims of this particular manipulation have yet progressed to cerebral signs of water intoxication, such as disorientation, restlessness, confusion, a reduced sensitivity to pain and partial or complete loss of consciousness ${ }^{5}$. However, such intoxication is not unknown in ultramarathon and triathlon events ${ }^{6-}$ 8 as a consequence of an excessive intake of water and potassium. Appropriate treatment includes the administration of hypertonic saline and/or furosemide or bicarbonate.

As with other athletic abuses, attempts at prevention by a warning of the dangers to health are unlikely to have a great success. However, it would be possible to determine the extent of the problem among body-builders and to correct the worst excesses by mandatory random assessment of blood electrolytes in top competitors.

\section{References}

1 Hursh LM. Food and water restriction in the wrestler. J Am Med Assoc 1979; 241: 915-6.

2 Yarrows SA. Weight loss through dehydration in amateur wrestling. J Am Diet Assoc 1988; 88: 491-3.

3 Woods ER, Wilson CD, Masland RP. Weight control methods in high school wrestlers. J Adolesc Health 1988; 9: 394-7.

4 Maffulli N. Making weight: a case study of two wrestlers. $\mathrm{Br} J$ Sp Med 1992; 26: 107-10.

5 Arieff AI, Llach F, Massey SG. Neurological manifestations and morbidity of hyponatremia: correlation with brain water and electrolytes. Medicine 1976; 55: 121-9.

6 Irving RA, Noakes TD, Buck R, van Zyl Smit $R$ et al. Evaluation of renal function and fluid homeostasis during recovery from exercise-induced hyponatremia. J Appl Physiol 1991; 70: 342-8.

7 Noakes TD, Norman RJ, Buck RH, Godlonton J, Stevenson K, Pittaway $\mathrm{D}$. The incidence of hyponatremia during prolonged ultraendurance exercise. Med Sci Sports Exerc 1990; 22: 165-70.

8 Frizzell RT, Lang GH, Lowance DC, Lathan SR. Hyponatremia and ultramarathon running. J Am Med Assoc 1985; 255: 772-4.

Effects of age, training background and duration of running on abnormal urinary findings after a half-marathon race

Hakan Gür MD, Selçuk Küçükoğlu MD, Esma Sürmen MD and Ayçe Müftüoğlu MD

Department of Sports Medicine, Medical School of Uludağ University, 16384 Görükle, Bursa, Turkey

Sir

Exercise-induced urinary abnormalities have been reported by several studies covering a wide range of running distances ${ }^{1-5}$ but there were insufficient data in the literature about the effects of age, duration of running and training background of subjects on urinary abnormalities after a half-marathon.

A total of 45 men marathon runners of mean(s.d.) age 29.7(11.74) years (range 16-59 years) and free from renal disease volunteered for this study. All runners filled out a questionnaire to determine their training and health background and completed the official distance of $21.1 \mathrm{~km}$, as part of the annual Second Green Bursa Half Marathon on 18 April 1992.

Each subject submitted a fresh urine specimen $2 \mathrm{~h}$ before and immediately after the race. Analysis of these specimens included laboratory determinations of glucose, bilirubin, ketones, specific gravity, blood, protein, urobilinogen, nitrite, leucocytes using Multi stix (Ames, Miles, Slough, UK) and microscopic analysis of the spun sediment, which are commonly used both for clinical and experimental determination of nephron function. Urine analysis before and after the race was completed within $4 \mathrm{~h}$ of voiding using standard procedures. All these variables together with age, half-marathon race time, number of completed half-marathon races and training distance per week were run through a stepwise regression procedure to see which characteristics were related to the abnormal urinary findings. 